\title{
Scar Endometriosis: Experience of a Surgeon
}

\author{
Tamanna Narmeen $* 1$, M M Masud Pervez ${ }^{2}$
}

\begin{abstract}
Introduction: Cesarean section is a common obstetric surgery worldwide. As incision wound in such a surgery is exposed abundantly to endometrial tissue, incision scar endometriosis can occur. This study reports a surgeon's experience in managing such an uncommon entity. The aim of this study was to identify risk factors for developing SCE and show the clinical spectrum of presentation. This study also shows our experience in surgical management of surgical scar endometriosis. Extra pelvic endometriosis is defined as the presence and growth of functional endometrial tissue outside the pelvis. Cesarean scar endometriosis (CSE) is a rare form of extra pelvic endometriosis that is usually confused with other surgical problems leading to delay in diagnosis. Materials and Methods: We reviewed the case records of patients who were diagnosed as CSE in the surgery department of BIRDEM GENERAL HOSPITAL-2 from September 2013 till September 2018. Results: We found 8 patients of scar endometriosis in 5 years making it one of the rare conditions. The age of the patients range 23-39 years and interval from symptoms to treatment varied from 16 months to 64 months. Five patients had presented to surgery department and 3 were referred from obstetric department. Cyclic pain and swelling in scar area were the most common presenting symptoms. All patients underwent excision of the mass with no recurrence of symptoms at a follow up ranging from 9 to 60 months. Conclusion: Increasing awareness of this condition among doctors can help in early diagnosis and treatment with gratifying results. Precaution during obstetrical surgery to avoid undue contamination of the wound can reduce incidence of scar endometriosis.
\end{abstract}

Keywords: Cesarean section, Scar endometriosis, Excision.

Number of Table: 01; Number of Figure: 01; Number of References: 25; Number of Correspondences: 02

* 1. Corresponding Author: Dr. Tamanna Narmeen

Assistant Professor

Department of Surgery

BIRDEM GENERAL HOSPITAL and IMC, Dhaka.

Email: tnarmeen@gmail.com

2. Dr. M M Masud Pervez

Associate Professor

Department of Pediatric Surgery

BIRDEM GENERAL HOSPITAL and IMC, Dhaka.

\section{Introduction}

Scar endometriosis is a variant of extra pelvic endometriosis. Extra pelvic endometriosis is defined as the presence and growth of functional endometrial tissue outside the pelvis ${ }^{1,2}$. Extra pelvic endometriosis is a rare condition ${ }^{3}$. Various sites of endometriosis reported outside pelvis are abdominal organs, lungs and pleura ${ }^{4,5}$. It can also arise from scar tissue especially after cesarean section. The term cesarean scar endometriosis (CSE) is an unusual manifestation of extra pelvic endometriosis. Scar endometriosis can easily be confused with abscess, lipoma, hematoma, sebaceous cyst, stitch granuloma, incisional hernia or tumors resulting in delay in diagnosis ${ }^{6}$. One of the most accepted theory about development of CSE is iatrogenic implantation. Here endometrial tissue is directly inoculated into the abdominal fascia or subcutaneous tissue and is subsequently stimulated by estrogen to produce endometriomas. The various clinical symptoms of CSE are due to proliferation of these cells under the influence of female hormones. Although CSE may present with various complaints, the most common clinical symptoms and signs are swelling, tenderness, cyclic pain and cyclic enlargement of swelling.

\section{Materials and Methods}

This was a observational, retrospective study performed at the surgery unit of BIRDEM GENERAL HOSPITAL-2. Data was collected from the recorded case history of 8 patients who underwent surgical management for CSE in our surgery unit from September 2013 till September 2018. It consisted of reviewing and analyzing data from the medical records of patients diagnosed with surgical scar endometriosis prior to their surgery. All patients had history of one or more cesarean sections, and their cesarean sections were performed in different hospitals. After the clinical assessment, the diagnosis was confirmed by ultrasonography and FNAC from swelling. In all cases, surgical excision was performed and the definitive diagnosis was confirmed by histopathological examination. All patients were operated under spinal anesthesia. Age, symptoms, size of tumor, interval between cesarean section and the onset of symptoms, and operative findings, were evaluated. Demographic features and operative findings of the cases are demonstrated in Table I.

\section{Results}

This study includes 8 patients who underwent surgical treatment for CSE. Fig. 1 shows excised endometrial tissue from one such patient. Three patients were referred from gynecologists and 5 patients visited surgery outpatient department with complaints of swelling with pain on or near previous cesarean scar. According to medical records, Pfannenstiel incision had been performed for cesarean section in all patients. Two patients also underwent tubal ligation during cesarean section. Their age ranged from 23 to 39 years. The common complaint of the patients was a palpable 
subcutaneous mass under the incision scar. Four patients suffered from cyclical pain. Continuous pain was seen in three patients, and 1 patient complained of enlargement of the nodule during the menstrual period but experienced no pain. The time interval between cesarean section and the onset of symptoms ranged from 16 to 64 months. The preoperative diagnosis was confirmed by history, examination, ultrasonography and FNAC from lump. All of the patients were treated surgically by removal of the lump. In 1 case the lesion extended into the muscle layer. Anatomical repair of fascia and muscle was done after wide excision of lump in this case. The diameter of the endometriotic lesions ranged from $1.5 \mathrm{~cm}$ to $5 \mathrm{~cm}$ in size.

Table-I: Demographic features and operative findings:

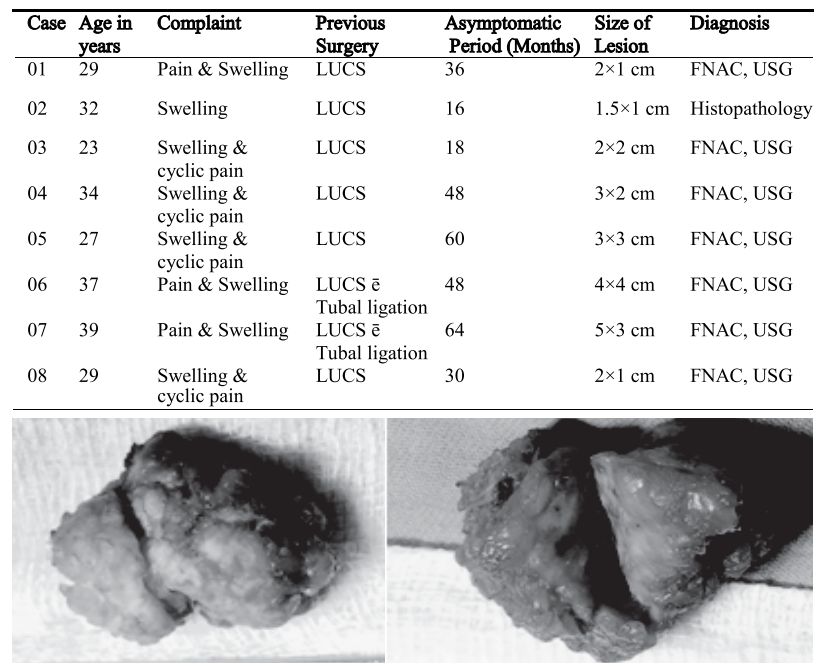

Figure-1: Excised endometrial tissue.

Discussion

Endometriosis in cesarean scar is a rare entity. There is only a few publications written on CSE; of them most are case reports. It is difficult to perform well-controlled studies of such rare problems. The common presentation of CSE includes a palpable subcutaneous nodule, with cyclic, noncyclic, or constant pain and aggravation of complaints during menstruation. Nodule under a cesarean section scar and cyclic aggravation of symptoms points to the diagnosis as CSE.

A case control study performed by De Oliveira et al. tried to identify the risk factors for development of scar endometriosis. According to this study, early hysterotomy in pregnancy especially before 22nd weeks of gestation is the main risk factor ${ }^{7}$. Early cesarean section causes more CSE, as early decidua seems to have more pluripotential capabilities and can result in enhanced cellular replication producing endometriosis ${ }^{8}$. The most important risk factor for developing scar endometriosis is a history of cesarean section ${ }^{9}$. Wang et al. in another study identified the cause of development of CSE. First of all, obstetric surgery exposes a large amount of endometrial cells to the wound, and these cells can be entrapped in the wound ${ }^{10}$. Amniotic fluid and more blood loss in case of obstetric surgery provide a relatively rich nutritional environment for the growth of endometrial tissue in the wound ${ }^{10}$.
In this study, the time interval between cesarean section and the onset of symptoms ranged from 16 to 64 months. The late onset of symptoms after surgery is the probable cause of misdiagnosis ${ }^{11}$. General surgeons infrequently manage such cases of scar endometriosis ${ }^{12}$. Preoperative diagnoses of surgical scar endometriosis is often difficult ${ }^{9}$. Proper history and physical examination can point towards accurate diagnosis.

Scar endometriosis usually develops in the superficial layers of anterior abdominal wall, and nodule is easily palpable. Ultrasonography supports the clinical findings. Ultrasound is accessible, reliable, and cost-effective procedure. Fine-needle aspiration cytology (FNAC) confirms diagnosis preoperatively. Imaging like computed tomography, and magnetic resonance imaging can be performed $^{12,13}$. Such imagings are nonspecific but useful for differential diagnoses and detecting the relationship between the mass and the other tissues. So imaging can be used to plan the extent of operative resection. Recognizing the typical clinical symptoms is the key for diagnostic accuracy.

The presence of hormone-sensitive tissue under the skin explains the symptoms reported by our patients, including cyclic pain, and swelling. Pain, either cyclic or noncyclic remained the major symptom, reported by more than $80 \%$ of patients in the cohort study of Zhang and Liu in China, Uçar et al. in Turkey, and Vellido-Cotelo et al. in Spain ${ }^{14,15,16}$. A nodule was present during examination of more than $90 \%$ of patients in these studies. With regard to imaging, ultrasound is the most accessible, reliable, and cost-effective technique for the diagnosis of CSE according to Hensen et al ${ }^{17}$.

Ultrasonography along with clinical examination allows to differentiate from incisional hernia, hematoma, abscess, cyst, or lipoma in most cases. In the study of Zhang and Liu, it also revealed deep infiltrations in $26 \%$ of patients, in which cases USG helped guide the surgical excision ${ }^{14}$. We encountered only 1 case out of 8 in which the lesion extended upto the muscle layer. Computed Tomography or Magnetic Resonance Imaging can be used in case of diagnostic doubt but they are rarely needed. Uçar et al. found no evidence of pelvic endometriosis associated for the 12 cases of CSE examined in their study ${ }^{15}$. Vellido-Cotelo et al. highlighted that there seem to be no linkages between pelvic and scar endometriosis development. In their study, $14 \%$ of patients had associated pelvic endometriosis, which corresponds to the incidence in the general population ${ }^{16}$. We found no associated pelvic endometriosis in our series of 8 patients.

Based on their clinical experience of fine needle aspiration cytology (FNAC) for 9 cases of CSE, Medeiros et al. reported that FNAC is a quick, cost-effective, and accurate diagnostic tool to include in patients' management ${ }^{18}$. In the study of Vellido-Cotelo et al., 52\% had a FNAC diagnosis before surgery and one of the patients was diagnosed with cancer by this method, which subsequently led to a different therapeutic management ${ }^{16}$. All 8 patients in our series 
had FNAC that suggested SCE. However, the use FNAC technique is controversial.Because some authors argue that there remains a risk of producing new endometriotic implants at the puncture site ${ }^{19}$.

In this case series, we did not find any evidence of pelvic endometriosis. Iatrogenic mechanical transplantations on incision scars during the operations are the most accepted pathogenesis. Aggressive behavior of endometriosis itself might also be a possible risk factor ${ }^{10}$.

Mostly, the reported cases have mentioned that the contamination have occurred during surgery and possible contact with endometrial tissue including episiotomy, hysterectomy, ectopic pregnancy, laparoscopy, tubal ligation, and cesarean section ${ }^{20,21}$. So it is important to take precautions during obstretical surgeries to avoid transplantation of endometrial cells. To minimize endometriotic contamination, some authors recommend careful isolation of the incision and lavage with saline before the closure of the wall ${ }^{22}$. Some authors also suggested if parietal and visceral peritoneum are not closed meticulously during closure of cesarean section, it may markedly increase the postoperative occurrence of $\mathrm{CSE}^{23}$. Replacing instruments and needles with a new one when suturing other abdominal layers is another suggestion by authors to avoid $\mathrm{CSE}^{24}$. Time of cesarean section is another risk factor of CSE according to some authors. Wicherek et al. stated that cesarean section performed before spontaneous onset of labor may increase the risk of occurrence of scar endometriosis $^{25}$.

Similarly in this study, all 8 patients had elective cesarean section without the presence of regular uterine contractions.

In the same way as in the literature reviewed, we recommend that surgical removal of the nodule should be the treatment of choice. Surgical resection reduces local recurrence and treatment failure. In our series of 8 patients we have followed up the cases from 09 to 60 months with no recurrence of symptoms. The excision may be technically difficult, depending on the size of the mass and if the lesion extends to deeper tissues, such as aponeurosis, muscle or, more rarely, peritoneum. Among the cases in the present study, only one case required dissection upto the muscle layer and anatomical repair was done to cover the defect after excision of the nodule.

\section{Conclusion}

Scar endometriosis is a rare entity. Cesarean section is a risk factor for appearance CSE. To prevent iatrogenic implantation of endometriotic tissue in the surgical wound additional attention should be given during surgeries that expose the endometrium. Typical history and proper examination leading to clinical suspicion supported by USG and FNAC will reduce diagnostic delay and allow appropriate management. Excision is the treatment of choice with good results. Precaution during obstretic surgery, and meticulous closure of wound can avoid such complications as scar endometriosis.
Conflict of Interests: None.

Accnowledgement

I thank the doctors of emergency department of BIRDEM GENERAL HOSPITAL -2 for their help and support in overall management of the patients of this study group.

\section{References}

1. G.K. Patterson, G.B. Winburn. Abdominal wall endometriomas: report of eight cases. Am Surg. 1999; 65: 36-39.

PMid:9915529

2. R.G. Blanco, V.S. Parithivel, A.K. Shah, M.A. Gumbs, M. Schein, P.H. Gerst Abdominal wall endometriomas . Am J Surg. 2003; 185: 596-598.

https://doi.org/10.1016/S0002-9610(03)00072-2

3. S.K. Chatterjee Scar endometriosis: a clinicopathologic study of 17 cases Obstet Gynecol. 1980; 56: 81-84.

PMid:7383492

4. N. Klinic, A. Yalinkaya, M. Ozaydin Nondecidualized and decidualized endometriosis of the abdominal wall (A report of two cases secondary to cesarean section). Turk J Med Sci. 2002; 32: 505-508.

5. A. Gaunt, G. Heard, E.S. McKain, B.M. Stephenson Caesarean scar endometrioma Lancet. 2004; 364: 368. https://doi.org/10.1016/S0140-6736(04)16726-3

6. K.E. Koger, C.H. Shatney, K. Hodge, J.H. McClenathan Surgical scar endometrioma Surg Gynecol Obstet. 1993; 177: 243-246.

PMid:8356497

7. de Oliveira MA, de Leon AC, Freire EC, de Oliveira HC. Risk factors for abdominal scar endometriosis after obstetric hysterotomies: a case-control study. Acta Obstet Gynecol Scand. 2007; 86: 73-80.

https://doi.org/10.1080/00016340601099346

PMid:17230293

8. L. Wicherek, M. Klimek, J. Skret-Magierlo. "The obstetrical history in patients with Pfannenstiel scar endometriomas - an analysis of 81 patients," Gynecologic and Obstetric Investigation. 2007; 63(2): 107-113.

https://doi.org/10.1159/000096083

PMid:17028436

9. Leite GK, Carvalho LF, Korkes H, Guazzelli TF, Kenj G, Viana Ade T. Scar endometrioma following obstetric surgical incisions: retrospective study on 33 cases and review of the literature. Sao Paulo Med J. 2009; 127: 270-277.

https://doi.org/10.1590/S1516-31802009000500005

PMid:20169275

10. Wang PH, Juang CM, Chao HT, Yu KJ, Yuan CC, Ng HT. Wound endometriosis: risk factor evaluation and treatment. J Chin Med Assoc. 2003; 66: 113-119.

PMid:12716010

11. Paşalega M, Mirea C, Vîlcea ID. Parietal abdominal endometriosis following cesarean section. Rom J Morphol Embryol. 2011; 52: 503-508.

PMid:21424102

12. Al-Jabri K. Endometriosis at caesarian section scar. Oman Med J. 2009; 24: 294-295.

https://doi.org/10.5001/omj.2009.59 
13. Francica G. Reliable clinical and sonographic findings in the diagnosis of abdominal wall endometriosis near cesarean section scar. World J Radiol. 2012; 4: 135-14.

https://doi.org/10.4329/wjr.v4.i4.135

PMid:22590667 PMCid:PMC3351681

14. J. Zhang, X. Liu. "Clinicopathological features of endometriosis in abdominal wall-clinical analysis of 151 cases." Clinical and Experimental Obstetrics and Gynecology. 2010; 43(3): 379-383.

15. M. G. Uçar, F. Şanlıkan, A. Göçmen. "Surgical treatment of scar endometriosis following cesarean section, a series of 12 cases." Indian Journal of Surgery. 2015; 77: 682-686.

https://doi.org/10.1007/s12262-013-0978-1

PMid:26730088 PMCid:PMC4692860

16. R. Vellido-Cotelo, J. L. Mu-oz-González, M. R. Oliver-Pérez. "Endometriosis node in Gynaecologic scars: a study of 17 patients and the diagnostic considerations in clinical experience in tertiary care center." BMC Women's Health. 2015; 15(1): 13.

https://doi.org/10.1186/s12905-015-0170-9

PMid:25783643 PMCid:PMC4337097

17. J.-H. J. Hensen, A. C. Van Breda Vriesman, J. B. C. M. Puylaert. "Abdominal wall endometriosis: clinical presentation and imaging features with emphasis on sonography." American Journal of Roentgenology. 2006; 186(3): 616-620.

https://doi.org/10.2214/AJR.04.1619

PMid: 16498086

18. F. D. C. Medeiros, D. I. M. Cavalcante, M. A. D. S. Medeiros, J. Eleutério Jr. "Fine-needle aspiration cytology of scar endometriosis: study of seven cases and literature review." Diagnostic Cytopathology. 2011; 39(1):18-21. https://doi.org/10.1002/dc.21319

PMid:20058306

19. G. K. C. Leite, L. F. P. De Carvalho, H. Korkes, T. F.
Guazzelli, G. Kenj, A. D. T. Viana. "Scar endometrioma following obstetric surgical incisions: retrospective study on 33 cases and review of the literature." Sao Paulo Medical Journal. 2009; 127(5): 270-277. https://doi.org/10.1590/S1516-31802009000500005 PMid:20169275

20. Chiang DT, Teh WT. Cutaneous endometriosis-surgical presentations of a gynaecological condition. Aust Fam Physician. 2006; 35: 887-888.

PMid: 17099809

21. Gunes M, Kayikcioglu F, Ozturkoglu E, Haberal A. Incisional endometriosis after cesarean section, episiotomy and other gynecologic procedures. J Obstet Gynaecol Res. 2005; 31: 471-475.

https://doi.org/10.1111/j.1447-0756.2005.00322.x

PMid: 16176520

22. Picod G, Boulanger L, Bounoua F, Leduc F, Duval G. Abdominal wall endometriosis after caesarean section: report of fifteen cases. Gynecol Obstet Fertil. 2006; 34: 8-13.

https://doi.org/10.1016/j.gyobfe.2005.11.002

PMid: 16406732

23. Minaglia S, Mishell DR, Jr, Ballard CA. Incisional endometriomas after cesarean section: a case series. J Reprod Med. 2007; 52: 630-634.

PMid: 17847762

24. Wasfie T, Gomez E, Seon S. Abdominal wall endometrioma after cesarean section: a preventable complication. Int Surg. 2002; 87:175-177.

PMid: 12403094

25. Wicherek L, Klimek M, Skret-Magierlo J. The obstetrical history in patients with Pfannenstiel scar endometriomas - an analysis of 81 patients. Gynecol Obstet Invest. 2007; 63:107-113.

https://doi.org/10.1159/000096083

PMid:17028436 